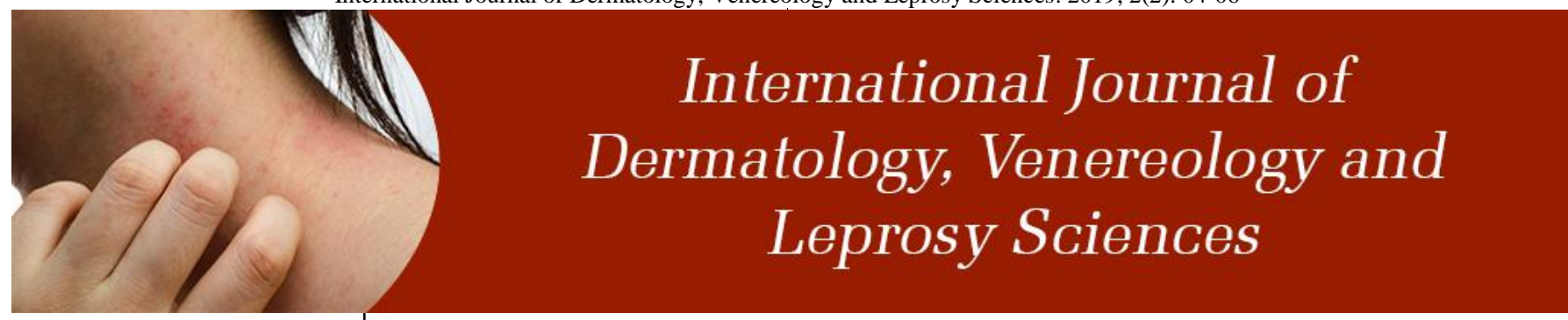

E-ISSN: 2664-942X

P-ISSN: 2664-9411

www.dermatologypaper.com/

Derma 2019; 2(2): 04-06

Received: 04-05-2019

Accepted: 06-06-2019

Gamini Randeniya

Department of Dermatology,

Medical Research Institute,

Colombo, Sri Lanka
Corresponding Author: Gamini Randeniya Department of Dermatology, Medical Research Institute, Colombo, Sri Lanka

\section{Assessment of heavy metal levels in patients with Telogen effluvium- A clinical study}

\section{Gamini Randeniya}

DOI: https://doi.org/10.33545/26649411.2019.v2.i2a.23

\begin{abstract}
Introduction: Telogen effluvium (TE) is the most common cause of diffuse hair loss. The present study was conducted to assess heavy metal levels in patients with Telogen effluvium.

Materials \& Methods: The present study was conducted on 138 cases of Telogen effluvium of both genders. Equal number of control was also included. The hair samples were placed between the microscopic slides and cover glass for microscopic examination of the hair shaft and root at $\times 40$ magnification. Serum $\mathrm{Fe}, \mathrm{Mg}, \mathrm{Mn}, \mathrm{Zn}, \mathrm{Pb}, \mathrm{Co}, \mathrm{Cd}$, and $\mathrm{Cu}$ concentrations were determined using a UNICAM- 929 spectrophotometer.

Results: Out of 138 patients, males were 78 and females were 60 . The mean cadmium level in group I was 0.21 and in group II was 0.017 , iron level was 4.64 in group I and 1.29 in group II, magnesium was 31.5 in group I and 23.1 in group II, lead was 0.27 in group I and 0.019 in group II, zinc was 1.32 in group I and 1.30 in group II, cobalt was 0.41 in group I and 0.02 in group II, copper level was 1.13 in group I and 0.45 in group II. The difference was significant $(P<0.05)$.

Conclusion: Authors found that patients with Telogen effluvium had significantly higher level of heavy metals than control.
\end{abstract}

Keywords: Hair, Telogen effluvium, Heavy metals

\section{Introduction}

Hair is a structure with utmost cosmetic importance that derives from ectoderm. It provides a significant contribution in terms of the maintenance of the self- image as well as healthy and productive social interactions. As compared to men, hair loss has a deeper impact in women on social interactions relative to the alterations in quality of life ${ }^{[1]}$. Despite these differences, hair loss is a significant source of concern for all individuals regardless of the age and gender. Hair is essential in identity of many women. Femininity, sexuality, attractiveness and personality are symbolically linked to woman's hair rather than in men. Women are more likely to have lowered quality of life and restricted social contacts as compared to men as a result of hair loss. Loss of hair becomes a matter of concern in all individuals irrespective of age and sex ${ }^{[2]}$.

Telogen effluvium (TE) is the most common cause of diffuse hair loss. There are other causes of diffuse hair loss, which include, female pattern hair loss, chronic TE, anagen effluvium, loose anagen hair syndrome, diffuse type of alopecia areata, congenital atrichia, congenital hypotrichosis and hair shaft abnormalities (hair breakage, unruly hair) ${ }^{[3]}$.

The first attempt to classify TE has been made by Headington ${ }^{[4]}$. Its classification, however, has never been applied possibly because of its difficulty. He divided TEs in three pathogenetic types: (1) premature teloptosis, (2) collective teloptosis, and (3) premature entry into the telogen phase. Those types share in common the copious shedding of hairs. In some cases, some of the types mentioned earlier may overlap ${ }^{[5]}$. The present study was conducted to assess heavy metal levels in patients with Telogen effluvium.

\section{Materials \& Methods}

The present study was conducted in the department of Dermatology. It comprised of 138 cases of Telogen effluvium of both genders. Equal number of control was also included. The study protocol was approved by the Ethics Committee. All were informed regarding the study and written consent was obtained.

Data such as name, age, gender etc was recorded. All patients were subjected to hair pull 
test. The hair samples were placed between the microscopic slides and cover glass for microscopic examination of the hair shaft and root at $\times 40$ magnification.

Blood samples were obtained into empty tubes in both groups, and the sera were separated with centrifugation at $3000 \mathrm{rpm}$ for $10 \mathrm{~min}$. The samples were stored at $-80 \mathrm{in}$ plastic tubes until the time of analysis. Serum Fe, Mg, Mn, $\mathrm{Zn}, \mathrm{Pb}, \mathrm{Co}, \mathrm{Cd}$, and $\mathrm{Cu}$ concentrations were determined using a UNICAM- 929 spectrophotometer. Results thus obtained were subjected to statistical analysis. P value less than 0.05 was considered significant.

\section{Results}

Table I: Distribution of patients

\begin{tabular}{|c|c|c|}
\hline \multicolumn{3}{|c|}{ Total- 138 } \\
\hline Gender & Male & Female \\
\hline Number & 78 & 60 \\
\hline
\end{tabular}

Table I shows that out of 138 patients, males were 78 and females were 60 .

Table II: Assessment of heavy metal level

\begin{tabular}{|c|c|c|c|}
\hline $\begin{array}{c}\text { Heavy } \\
\text { metals }\end{array}$ & $\begin{array}{c}\text { Group I } \\
\text { (Cases) }\end{array}$ & $\begin{array}{c}\text { Group II } \\
\text { (Control) }\end{array}$ & $\begin{array}{c}\text { P } \\
\text { value }\end{array}$ \\
\hline Cadmium & 0.21 & 0.017 & 0.01 \\
\hline Iron & 4.64 & 1.29 & 0.03 \\
\hline Magnesium & 31.5 & 23.1 & 0.01 \\
\hline Lead & 0.27 & 0.019 & 0.02 \\
\hline Zinc & 1.32 & 1.30 & 0.91 \\
\hline Cobalt & 0.41 & 0.02 & 0.05 \\
\hline Copper & 1.13 & 0.45 & 0.02 \\
\hline
\end{tabular}

Table II, graph I shows that mean cadmium level in group I was 0.21 and in group II was 0.017 , iron level was 4.64 in group I and 1.29 in group II, magnesium was 31.5 in group I and 23.1 in group II, lead was 0.27 in group I and 0.019 in group II, zinc was 1.32 in group I and 1.30 in group II, cobalt was 0.41 in group I and 0.02 in group II, copper level was 1.13 in group I and 0.45 in group II. The difference was significant $(P<0.05)$.

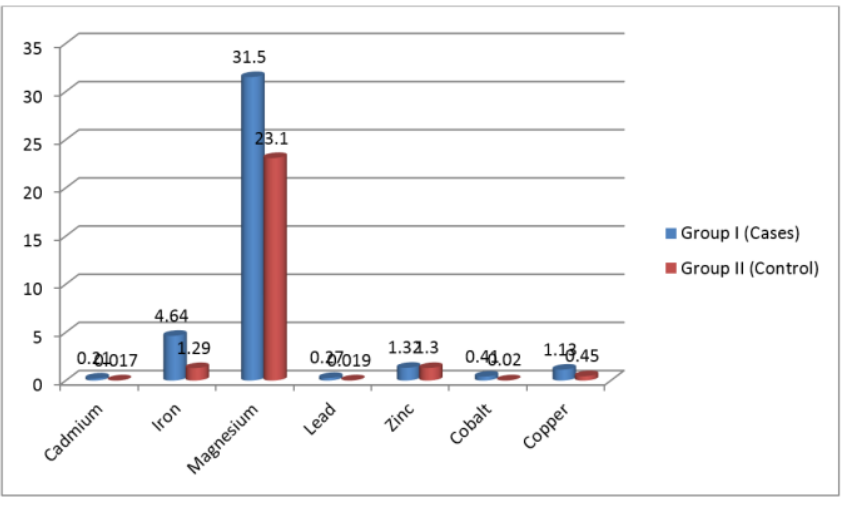

Graph I: Assessment of heavy metal level

\section{Discussion}

Hair cycle implies sequential phases of growth and rest that each follicle goes through which includes anagen (active hair growth), catagen (involution) and telogen phase (resting). The anagen phase may last for about 2 to 8 years, the catagen phase lasts for 4 to 6 weeks and the telogen phase lasts for 2 to 3 months ${ }^{[6]}$. The exogen phase of hair follicle (the release of telogen hair) coincides with the end of telogen phase. In the normal scalp, $90-95 \%$ of the hair follicles are in the anagen phase and the remainder (5-10\%) in the telogen phase with about 100-150 hair being shed daily. Only a few follicles will be in the transitional or catagen phase ${ }^{[7]}$. The biological clock that determines the end of the anagen phase and the beginning of the catagen/telogen phase is a complex phenomenon whose molecular basis is being unveiled. Various metabolic alterations such as pregnancy, malnutrition and other stressful conditions are capable of influencing the biological clock within hair follicles and it is possible for abnormally large number of hair follicles to enter the telogen phase simultaneously. TE occurs if a significant number of anagen hair are triggered to stop growing prematurely by any stimulus and subsequently enter catagen phase, followed by telogen phase. After about 2-3 months of initial insult there is excessive hair shedding ${ }^{[8]}$. The present study was conducted to assess heavy metal levels in patients with Telogen effluvium.

In this study, out of 138 patients, males were 78 and females were 60 . Yavuz et al. ${ }^{[9]}$. assessed the heavy metal and trace element levels in patients with chronic TE. A total of 40 subjects with chronic TE were included in the study, and 30 healthy women served as control. General and dermatological examinations were taken up in all individuals. In spite of an absence of significant differences in terms of average $\mathrm{Zn}$ concentration, weight, or height between patients and controls, significant differences were noted for $\mathrm{Cd}, \mathrm{Fe}, \mathrm{Mg}, \mathrm{Mn}, \mathrm{Pb}, \mathrm{Co}$, and $\mathrm{Cu}(P<0.05)$.

We found that the mean cadmium level in group I was 0.21 and in group II was 0.017 , iron level was 4.64 in group I and 1.29 in group II, magnesium was 31.5 in group I and 23.1 in group II, lead was 0.27 in group I and 0.019 in group II, zinc was 1.32 in group I and 1.30 in group II, cobalt was 0.41 in group I and 0.02 in group II, copper level was 1.13 in group I and 0.45 in group II.

TE course may be acute or chronic when its duration exceeds 6 months. Of course, some of the forms described above cannot be chronic. A typical acute course is that of post-partum TE. In the autoimmune TE, instead, the course is characteristically chronic, with intermittent episodes of improvement. The severity of any relapse can be assessed by MWT, but it is often impossible to establish its possible cause. Intermittency, however, is important especially because the spontaneous recovery that can intervene in the course of any chronic TE may be erroneously credited to the therapy. This may explain some of the "successes" of popular treatments which cannot be but placebos and make any controlled study difficult to undertake ${ }^{[10]}$.

\section{Conclusion}

Authors found that patients with Telogen effluvium had significantly higher level of heavy metals than control.

\section{References}

1. Rebora A, Guarrera M, Drago F. Postpartum telogen effluvium. J Eur Acad Dermatol Venereol. 2016; 30:518

2. Dinh QQ, Sinclair R. Female pattern hair loss: Current treatment concepts. Clin Interv Aging. 2007; 2:189- 99.

3. Rebora A. Telogen effluvium. Dermatology. 1997; 195:209-212.

4. Headington JT. Telogen effluvium. New concepts and 
review. Arch Dermatol. 1993; 129:356-363.

5. Malkud S. Telogen effluvium: A review. J Clin Diagn Res. 2015; 9:01.

6. Sinclair R. Diffuse hair loss. Int J Dermatol. 1999; 38:8-18.

7. Morais S, e Costa FG, de Lourdes Pereira M. Heavy metals and human health. Environmental Health- Emerging Issues and Practice. Oosthuizen J ed: InTech, 2012.

8. Izah SC, Inyang IR, Angaye TC, Okowa IP. A review of heavy metal concentration and potential health implications of beverages consumed in Nigeria. Toxics 2016; 5:1.

9. Yavuz IH, Yavuz GO, Bilgili SG, Demir H, Demir C. Assessment of heavy metal and trace element levels in patients with telogen effluvium. Indian J Dermatol. 2018; 63:246-50.

10. Hamad WA, Said AF, Hamid A. Role of some trace elements in the pathogenesis of telogen effluvium in Egyptian females. J Egypt Women Dermatol. 2010; 7:44- 8 . 